\title{
Análise Bibliométrica dos Artigos sobre Controladoria Publicados em Periódicos dos Programas de Pós- Graduação em Ciências Contábeis Recomendados pela
} Capes

\begin{abstract}
Adriano José da Silva Mestrado em Ciências Contábeis pela Universidade Regional de Blumenau - FURB Professor da Universidade de Passo Fundo - UPF BR 285 Km 171, (UPF/FEAC). Passo Fundo/RS. CEP: 99052-900 E-mail: ajs@upf.br

Jorge Ribeiro de Toledo Filho Doutorado em Controladoria e Contabilidade pela Universidade de São Paulo - USP Professor da Universidade de São Paulo - USP Rua Antonio Veiga, 104 (FURB/PPGCC). Blumenau/SC. CEP: 89012-900 E-mailjtoledo@usp.br

Juliana Pinto Mestrado em Ciências Contábeis pela Universidade Regional de Blumenau - FURB Rua Antonio Veiga, 104 (FURB/PPGCC). Blumenau/SC. CEP: 89012-900 E-mail: julianapinto@smo.com.br
\end{abstract}

\section{RESUMO}

O objetivo deste artigo é analisar as referências utilizadas nas publicações sobre Controladoria, encontradas nos títulos, resumo e palavras-chave nos periódicos editados pelos Programas de Pós-Graduação em Ciências Contábeis recomendados pela CAPES. A metodologia utilizada na pesquisa é descritiva quanto aos objetivos, com abordagem quantitativa e do tipo levantamento. Na escolha dos artigos tomou-se como base a existência do termo "Controladoria" no título, no resumo ou nas palavraschave, observando-se a bibliografia referenciada nos artigos publicados. A população compreende 17 programas recomendados pela CAPES, sendo a amostra composta por 8 programas que disponibilizam o acesso aos periódicos por meio eletrônico. Como resultado da análise bibliométrica realizada, constata-se que $55,4 \%$ das referências utilizadas nos artigos pesquisados são internacionais, o que revela a existência de um amplo espaço para pesquisas sobre Controladoria no Brasil.

Palavras Chave: Controladoria. Periódicos. Programas de Pós-Graduação em Ciências Contábeis.

Bibliometric Analysis of Articles about Controllership Published in Periodicals of Post-Graduation Programs in Accounting Recommended by Capes 


\section{ABSTRACT}

The objective of this study is to analyze the references used in publications on Controllership, found in the titles, abstracts and key-words in the periodicals elaborated by the Post-Graduate Programs in Accounting recommended by CAPES. The methodology used to conduct this search, about the objectives, was of descriptive type. About the procedures was classified as survey with quantitative approach. The criterion for selecting the articles was the use of the word "Controllership" in the title, summary or key-words, looking at the referenced literature in published articles. The population comprised 17 programs recommended by CAPES. The sample was composed by 8 recommended programs that provide access to the periodicals by the internet way. As a final result of bibliometric analysis, it was found that $55.4 \%$ of the references used in surveyed articles are international.

Keywords: Controllership. Periodicals. Accounting Post-Graduate Programs.

\section{INTRODUÇÃO}

Com o desafio cada vez mais crescente de profissionalizar a gestão e melhorar os índices de produtividade das entidades, a Contabilidade passa a ser fundamental no atual ciclo de desenvolvimento empresarial, devendo atualizar-se em suas práticas e objetivos para proporcionar meios mais eficientes e eficazes de oferecer suporte para a gestão e a tomada de decisão. Essas demandas, decorrentes das mudanças no ambiente empresarial, fazem com que o planejar, dirigir, organizar e controlar sejam cada vez mais necessários e mesmo imprescindíveis para a manutenção das empresas ao longo do tempo.

Nesse cenário, a Controladoria, cujo surgimento se deu nos Estados Unidos no século XX, devido, principalmente, a verticalização, diversificação e expansão geográfica das entidades, o que criou uma maior complexidade de suas atividades (Beuren, 2002), passa a ser de vital importância nas organizações, para zelar e informar quanto ao cumprimento dos objetivos estabelecidos pela direção, devendo, pois, ser estudada e aperfeiçoada para uma melhor gestão das empresas.

Nessa linha desenvolve-se esse estudo, cujo objetivo é analisar as referências utilizadas nas publicações sobre Controladoria encontradas nos títulos, resumos e 
palavras-chave nos Periódicos editados até o final de 2006 pelos Programas de PósGraduação em Ciências Contábeis recomendados pela CAPES.

\section{REFERENCIAL TEÓRICO}

\subsection{Controladoria}

O nascimento da Controladoria, de acordo com Beuren (2002, p.20), se situa "no século XX nas grandes corporações norte-americanas, com a finalidade de realizar rígido controle de todos os negócios das empresas relacionadas, subsidiárias e/ou filiais".

Beuren (2002) assinala que as empresas começaram a se fundir no final do século XIX, tornando-se grandes empresas, organizadas sob a forma de divisões, mas com controle centralizado. Segundo a autora, o crescimento vertical e diversificado desses conglomerados exigia, por parte dos acionistas e gestores, um controle na central em relação aos departamentos e divisões que rapidamente se espalhavam nos Estados Unidos e em outros países.

Para Borinelli (2006, p.105), a "controladoria é um conjunto de conhecimentos que se constituem em bases teóricas e conceituais de ordens operacional, econômica, financeira e patrimonial, relativas ao controle do processo de gestão organizacional". Catelli (2001, p.344), por seu turno, considera que

a controladoria, enquanto ramo do conhecimento, apoiada na Teoria da Contabilidade numa visão multidisciplinar, é responsável pelo estabelecimento das bases teóricas e conceituais necessárias para a modelagem, construção e manutenção de Sistemas de Informações e Modelo de Gestão Econômica, que supram adequadamente as necessidades informativas dos Gestores e os induzam durante o processo de gestão, quando requerido, a tomarem decisões ótimas.

A Controladoria é também considerada como uma unidade administrativa, sendo definida como uma área da organização à qual é delegada autoridade para 
tomar decisões sobre eventos, transações e atividades que possibilitem o adequado suporte ao processo de gestão. Portanto, por ser tratar de uma ciência nova, a Controladoria não tem um conceito definitivo, já que os autores têm diferentes opiniões sobre o tema (Peleias, 2002).

\subsection{Bibliometria}

A bibliometria vem sendo empregada como ferramenta para medir a produção científica. Fazer o levantamento do inventário das atividades científicas, nos mais diversos campos do conhecimento, implica em uma busca criteriosa nas publicações, pois o homem busca e apresenta constantemente novos conhecimentos, fazendo com que as informações circulem e se disseminem por todas as partes do mundo.

A análise dos indicadores bibliométricos permite, por meio de análise estatística, quantificar a produção científica e técnica. Segundo Saes (2000, p.10-11), os indicadores bibliométricos são empregados por dois motivos:

O primeiro para analisar o tamanho, crescimento e distribuição da bibliografia científica (livros, revistas, patentes e outros), a fim de melhorar as atividades de informação, documentação e comunicação científica e o segundo para analisar os processos de geração, propagação e uso da literatura científica com a finalidade de conhecermos os mecanismos da investigação científica enquanto atividade social e a dinâmica e estrutura dos grupos de investigadores que produzem e utilizam esta literatura.

Um dos primeiros autores a realizar trabalhos e conceituar a bibliometria na Argentina foi, segundo Rios (2000), José Domingo Buonocuore (1952). Buonocuore (1952 apud Rios, 2000) menciona que a técnica de calcular a extensão ou medida da tomada de livros leva em conta vários coeficientes, formato, tipos de papel, quantia de palavras, peso do papel, etc. $\mathrm{Na}$ antigüidade, os gregos tinham inventado um processo para determinar a extensão dos manuscritos. Esta medida não só era útil como evitava supressões e interpretações no texto, mas também servia para determinar o preço do trabalho e o pagamento devido. 
Em 1969, Pritchard definia a bibliometria como sendo a "a aplicação de métodos matemáticos e estatísticos a livros, artigos e outras mídias de comunicação". Bufrem e Prates (2005) destacam que as leis bibliométricas mais comumente utilizadas e relacionadas à produtividade científica (Lei de Lotka), à dispersão da produção científica (Lei de Bradford) e à ocorrência de palavras no texto (Lei de Zipf), cujas aplicações originais foram cedendo lugar a modificações e incorporações, estruturaram-se em um corpo teórico que justificou o status de ciência ao conjunto de conhecimentos que então se configurava em torno do objeto informação.

A bibliometria, aplicada com um elevado grau de rigor metodológico, torna-se uma importante ferramenta para analisar a produção científica e quantificar a evolução do conhecimento produzido pelo homem.

\section{METODOLOGIA}

\subsection{Classificação da Pesquisa}

A pesquisa realizada pode ser classificada quanto ao seu objetivo como descritiva, ou seja, "a pesquisa que observa, registra, analisa e correlaciona fatos ou fenômenos (variáveis) sem manipulá-los". Quanto a sua abordagem a pesquisa é quantitativa e os procedimentos técnicos adotados se enquadram no tipo denominado de documental (Cervo; Bervian, 2002, p.66).

A abordagem quantitativa, segundo Richardson (1999), se define pelo emprego de quantificação tanto nas modalidades de coleta de informações, quanto no tratamento delas por meio de técnicas estatísticas, desde as mais simples como percentuais, médias, desvio-padrão, às mais complexas como coeficiente de correlação, análise de regressão, etc.

\subsection{Coleta dos Dados}

O levantamento de dados para esta pesquisa ocorreu da seguinte forma: (a) utilizou-se como critério de escolha os artigos que apresentassem o termo "Controladoria" no título, no resumo ou nas palavras-chave; (b) examinou-se a 
bibliografia referenciada nos artigos apresentados, sendo realizada a catalogação com todos os dados levantados a saber: livros nacionais e internacionais, teses e dissertações nacionais e internacionais, periódicos nacionais e internacionais, anais de eventos científicos nacionais e internacionais, sítios pesquisados na internet nacionais e internacionais, jornais e magazines nacionais e internacionais, além de palestras, relatórios, conferências e anotações de aula.

\subsection{População e Amostra}

A pesquisa foi desenvolvida por meio de consultas nos sítios dos Programas de Mestrado em Ciências Contábeis recomendados pela CAPES, sendo que do total de 17 programas recomendados, somente 8 editam periódicos científicos acessíveis por meio eletrônico, os quais constituem a amostra da pesquisa.

$\mathrm{Na}$ Tabela 1 consta uma descrição dos dados levantados, contendo o nome do periódico, a classificação no Qualis CAPES, o ano da primeira publicação do periódico até 0 ano de 2006, a periodicidade de circulação, o número total de edições encontradas nos sítios, o total de artigos encontrados nos sítios, o total de artigos encontrados com o tema "Controladoria" e o percentual de artigos pesquisados sobre o tema. 
Análise Bibliométrica dos Artigos sobre Controladoria Publicados em Periódicos dos Programas de Pós-Graduação em Ciências Contábeis Recomendados pela Capes

Adriano José da Silva, Jorge Ribeiro de Toledo Filho, Juliana Pinto

Tabela 1 - Periódicos dos Programas de Mestrado em Ciências Contábeis recomendados pela CAPES acessíveis por meio eletrônico

\begin{tabular}{|c|c|c|c|c|c|c|c|}
\hline $\begin{array}{l}\text { Nome do } \\
\text { periódico }\end{array}$ & $\begin{array}{l}\text { Qualis } \\
\text { CAPES }\end{array}$ & $\begin{array}{c}\text { Ano } \\
\text { Publicação }\end{array}$ & Periodicidade & $\begin{array}{l}\text { Total de } \\
\text { Edições }\end{array}$ & $\begin{array}{c}\text { N..- total } \\
\text { de } \\
\text { Artigos }\end{array}$ & $\begin{array}{c}\text { Artigos } \\
\text { Selecionados }\end{array}$ & $\%$ \\
\hline $\begin{array}{c}\text { Revista de } \\
\text { Contabilidade } \\
\text { Vista \& Revista - } \\
\text { UFMG }\end{array}$ & LA & 1989/2006 & Trimestral & 4 & 25 & 0 & \\
\hline $\begin{array}{c}\text { UnB Contábil - } \\
\text { UNB }\end{array}$ & $\mathrm{NC}$ & $2003 / 2006$ & Semestral & 6 & 63 & 0 & \\
\hline $\begin{array}{l}\text { Revista Universo } \\
\text { Contábill- FURB }\end{array}$ & $\mathrm{NC}$ & $2005 / 2006$ & Quadrimestral & 6 & 36 & 1 & 0,2 \\
\hline $\begin{array}{c}\text { Revista } \\
\text { Contemporânea } \\
\text { de Contabilidade } \\
\text { UFSC }\end{array}$ & & $2004 / 2006$ & Semestral & 6 & 37 & 1 & 0,2 \\
\hline $\begin{array}{l}\text { Revista Brasileira } \\
\text { de Gestão de } \\
\text { Negócios - RBGN } \\
\text { - FECAP }\end{array}$ & NB & $2004 / 2006$ & Quadrimestral & 4 & 24 & 0 & \\
\hline $\begin{array}{c}\text { BBR - Brazilian } \\
\text { Business Review } \\
\text { - FUCAPE }\end{array}$ & & $2004 / 2006$ & Quadrimestral & 7 & 31 & 1 & 0,2 \\
\hline $\begin{array}{c}\text { Revista Base - } \\
\text { Unisinos }\end{array}$ & Local A & $2004 / 2006$ & Quadrimestral & 5 & 29 & 0 & \\
\hline $\begin{array}{c}\text { Revista } \\
\text { Contabilidade \& } \\
\text { Finanças - } \\
\text { EAC/USP } \\
\end{array}$ & NA & 1989/2006 & Quadrimestral & 42 & 262 & 6 & 1,18 \\
\hline Total & & & & 80 & 507 & 9 & 1,78 \\
\hline
\end{tabular}

Fonte: dados da Pesquisa.

Conforme se observa na tabela 1, foram identificados 8 periódicos dos Programas de Mestrado em Ciências Contábeis recomendados pela CAPES, acessíveis por meio eletrônico. Foram encontradas nos sítios dos periódicos 80 edições disponíveis para pesquisa, com um total de 507 artigos. Deste total, foram localizados somente 9 artigos contendo o termo "Controladoria" no título, palavraschave e resumo, o que corresponde a $1,78 \%$.

Observa-se, também, que o periódico que mais publicou artigos contendo o termo "Controladoria" foi a Revista Contabilidade \& Finanças da FEA- USP com um total de seis artigos desde o ano de 1989, perfazendo um percentual de 1,18\% do total de artigos. Na seqüência aparecem: Revista Universo Contábil - FURB, Revista Contemporânea de Contabilidade - UFSC e a Brazilian Business Review - FUCAPE, 
respectivamente, com um artigo publicado em cada periódico, perfazendo um total de $0,6 \%$ do número total de artigos.

\section{APRESENTAÇÃO E ANÁLISE DOS DADOS}

Nesta parte da pesquisa a análise está dividida por periódico, onde se buscou categorizar a análise da bibliografia referenciada nos artigos publicados. As tabelas a seguir descrevem somente os itens citados.

A classificação é descrita da seguinte forma: a) livros nacionais e internacionais; b) teses e dissertações nacionais e internacionais; c) periódicos nacionais e internacionais; d) anais de eventos científicos nacionais e internacionais; e) sítios pesquisados na web nacionais e internacionais; f) jornais e magazines nacionais e internacionais; g) outros tipos nacionais e internacionais, compreendendo palestras, relatórios, conferências, anotações de aula; h) referências citadas até o ano de 2000 e após o ano de 2000.

A Tabela 2 descreve o tipo de bibliografia, o total por tipo, o percentual por tipo de bibliografia encontrada, o total geral e o percentual total das bibliografias referenciadas nos artigos da Revista Contabilidade \& Finanças. 
Análise Bibliométrica dos Artigos sobre Controladoria Publicados em Periódicos dos Programas de Pós-Graduação em Ciências Contábeis Recomendados pela Capes

Adriano José da Silva, Jorge Ribeiro de Toledo Filho, Juliana Pinto

Tabela 2 - Referências dos artigos publicados sobre Controladoria na Revista Contabilidade \& Finanças da FEA-USP

\begin{tabular}{|c|c|c|c|c|c|}
\hline Tipo de Bibliografia & & Total por tipo & $\%$ & Total geral & $\%$ \\
\hline \multirow{2}{*}{ Livros } & Nacional & 59 & 25,11 & \multirow[b]{2}{*}{176} & \multirow[b]{2}{*}{74,89} \\
\hline & Internacional & 117 & 49,79 & & \\
\hline \multirow{2}{*}{ Teses e Dissertações } & Nacional & 6 & 2,55 & \multirow[b]{2}{*}{6} & \multirow[b]{2}{*}{2,55} \\
\hline & Internacional & & & & \\
\hline \multirow{2}{*}{ Periódicos } & Nacional & 14 & 5,96 & \multirow[b]{2}{*}{29} & \multirow[b]{2}{*}{12,34} \\
\hline & Internacional & 15 & 6,38 & & \\
\hline \multirow{2}{*}{ Sites Web } & Nacional & 2 & 0,85 & \multirow[b]{2}{*}{4} & \multirow[b]{2}{*}{1,7} \\
\hline & Internacional & 2 & 0,85 & & \\
\hline \multirow{2}{*}{ Jornais e Magazines } & Nacional & 5 & 2,13 & \multirow[b]{2}{*}{14} & \multirow[b]{2}{*}{5,96} \\
\hline & Internacional & 9 & 3,83 & & \\
\hline \multirow{2}{*}{ Outros tipos } & Nacional & 5 & 2,13 & \multirow[b]{2}{*}{6} & \multirow[b]{2}{*}{2,56} \\
\hline & Internacional & 1 & 0,42 & & \\
\hline Total & & 235 & 100 & 235 & 100 \\
\hline
\end{tabular}

Fonte: dados da pesquisa.

Nos artigos publicados na revista Contabilidade \& Finanças contendo o termo "controladoria", há uma grande predominância de livros citados como referência bibliográfica, na medida em que do total de 235 citações, 176 referem-se a livros, o que representa um percentual de 74,9\%. Dos 176 livros citados, 59 livros ou 25,11\% são publicados no Brasil e 117 ou 49,79\% publicados na Europa ou nos Estados Unidos.

Quanto às Teses de Doutorado e Dissertações de Mestrado, somente foram referenciadas aquelas defendidas no Brasil, num total de seis, o que representa um percentual de $2,55 \%$.

Nota-se uma divisão quase que igualitária no uso de periódicos nacionais (14) e internacionais (15), correspondendo individualmente a 5,96\% e 6,38\%, respectivamente. Em relação a anais e eventos científicos, tanto nacionais quanto internacionais, não houve citação no referido periódico. Já sítios da internet, nacionais e internacionais, constam dois de cada, significando uma participação percentual de $1,70 \%$. 
No que se refere a Jornais e Magazines foram encontradas 14 citações, sendo nove editados no exterior e cinco nacionais, com um percentual de $5,96 \%$ do total de citações.

As citações descritas como "outros tipos" nacionais e internacionais, compreendendo palestras, relatórios, conferências, anotações de aula, foram citadas seis vezes, significando $2,56 \%$ do total de citações. As fontes internacionais correspondem a 5 e uma fonte é nacional.

$\mathrm{Na}$ Tabela 3, estão apresentadas as referências bibliográficas citadas nos artigos publicados na Revista Contabilidade \& Finanças. A divisão das obras publicadas e citadas foi realizada da seguinte forma: obras citadas até o ano $2000 \mathrm{e}$ obras citadas depois do ano 2000. Na seqüência apresenta-se a tabela com a respectiva classificação.

Tabela 3 - Referências publicadas e citadas na Revista Contabilidade \& Finanças até o ano de 2000

\begin{tabular}{|c|c|c|c|c|c|}
\hline \multirow{2}{*}{ Tipo de Bibliografia } & & Até o ano 2000 & $\%$ & Total Geral & $\%$ \\
\hline \multirow{3}{*}{ Livros } & Nacional & 57 & 30,65 & 152 & 81,72 \\
\cline { 2 - 6 } & Internacional & 95 & 51,08 & 0 & 0 \\
\hline \multirow{2}{*}{ Teses e Dissertações } & Nacional & 5 & 2,69 & 5 & 2,69 \\
\cline { 2 - 6 } & Internacional & 0 & 0 & 0 & 0 \\
\hline \multirow{2}{*}{ Periódicos } & Nacional & 8 & 4,3 & 14 & 7,53 \\
\cline { 2 - 6 } & Internacional & 6 & 3,23 & 0 & 0 \\
\hline \multirow{2}{*}{ Jornais e Magazines } & Nacional & 3 & 1,61 & 10 & 5,38 \\
\cline { 2 - 6 } & Internacional & 7 & 3,76 & 0 & 0 \\
\hline \multirow{2}{*}{ Outros tipos } & Nacional & 4 & 2,15 & 5 & 2,68 \\
\cline { 2 - 6 } & Internacional & 1 & 0,53 & 0 & 0 \\
\hline \multirow{2}{*}{ Total por período } & & $\mathbf{1 8 6}$ & $\mathbf{1 0 0}$ & $\mathbf{1 8 6}$ & $\mathbf{1 0 0}$ \\
\hline
\end{tabular}

Fonte: dados da pesquisa

Observa-se que do total de 235 obras citadas, 186 foram publicadas até o ano 2000, o que corresponde a $79,15 \%$. O total de livros publicados é de 152 , o que representa um percentual de $81,72 \%$. Desse percentual, 30,65\% referem-se a livros publicados no Brasil e 51,08\% a livros publicados na Europa e nos Estados Unidos. 
As teses e dissertações defendidas antes do ano de 2000 são em número de 5, o que corresponde a $2,69 \%$ do total de citações, sendo que somente foram citadas as teses e dissertações defendidas no Brasil.

Dos periódicos publicados e citados, 14 são anteriores ao ano de 2000 , representando $7,53 \%$ das citações. Os periódicos nacionais publicados e citados até 0 ano 2000 são em número de 8 , representando $4,3 \%$ do total, e os periódicos internacionais publicados e citados até o ano de 2000 são em número de 6, ou seja, $3,23 \%$ do total de citações. Anais, eventos científicos e sítios da Web não foram citados nos artigos publicados na revista. Jornais e Magazines foram citados 10 vezes, representando $5,38 \%$ do total de citações, sendo 3 nacionais e 7 internacionais. As citações descritas como "outros tipos" nacionais e internacionais foram citadas 5 vezes, correspondendo a um percentual de $2,68 \%$.

Tabela 4 - Referências publicadas e citadas na Revista Contabilidade \& Finanças posteriores ao ano de 2000

\begin{tabular}{|c|c|c|c|c|c|}
\hline \multirow{3}{*}{ Tipo de Bibliografia } & & $\begin{array}{c}\text { Depois do ano } \\
\mathbf{2 0 0 0}\end{array}$ & $\mathbf{\%}$ & Total Geral & $\%$ \\
\hline \multirow{2}{*}{ Livros } & Nacional & 10 & 20,41 & 24 & 48.98 \\
\cline { 2 - 6 } & Internacional & 14 & 28,57 & 0 & 0 \\
\hline \multirow{2}{*}{ Teses e Dissertações } & Nacional & 1 & 2,04 & 1 & 2,04 \\
\cline { 2 - 6 } & Internacional & 0 & 0 & 0 & 0 \\
\hline \multirow{2}{*}{ Periódicos } & Nacional & 6 & 12,24 & 15 & 30,62 \\
\cline { 2 - 6 } & Internacional & 9 & 18,38 & 0 & 0 \\
\hline \multirow{2}{*}{ Sites Web } & Nacional & 2 & 4,08 & 4 & 8,16 \\
\cline { 2 - 6 } & Internacional & 2 & 4,08 & 0 & 0 \\
\hline \multirow{2}{*}{ Jornais e Magazines } & Nacional & 2 & 4,08 & 4 & 8,16 \\
\cline { 2 - 6 } & Internacional & 2 & 4,08 & 0 & 0 \\
\hline \multirow{2}{*}{ Outros tipos } & Nacional & 1 & 2,04 & 1 & 2,04 \\
\cline { 2 - 6 } & Internacional & 0 & 0 & 0 & 0 \\
\hline Total por período & & $\mathbf{4 9}$ & $\mathbf{1 0 0}$ & $\mathbf{4 9}$ & $\mathbf{1 0 0}$ \\
\hline
\end{tabular}

Fonte: Dados da pesquisa

Examinando-se a tabela 4, nota-se que do total de 235 citações encontradas nos artigos publicados na Revista Contabilidade \& Finanças, somente 49 publicações citadas nas referências bibliográficas foram publicadas depois do ano de 2000, representando $20,85 \%$ das referências citadas. 
Os livros citados que foram publicados após o ano de 2000 totalizam 24, representando um percentual de $48,98 \%$ do total de citações publicadas e citadas nos artigos da revista.

Teses de Doutorado e Dissertações de Mestrado defendidas após o ano de 2000 foram citadas somente uma vez, perfazendo um percentual de 2,04\% das citações. Cabe ressaltar que a única citação nesse item é de tese e dissertação nacional.

No item periódico, foram levantadas 15 citações, que representam $30,62 \%$ do total de citações encontradas nos artigos publicados. Desses 15 periódicos citados, 6 são de circulação nacional e 9 de circulação internacional, que representam respectivamente $12,24 \%$ e $18,38 \%$ do total de publicações citadas posteriores ao ano de 2000.

No item Anais e Eventos Científicos não ocorreu qualquer citação. Sítios da web citados nas referências bibliográficas são em número de 4, representando $8,16 \%$ do total das citações. Nota-se nesse item um número igual de citações, sendo 2 nacionais e 2 internacionais, correspondendo a 4,08\%, respectivamente. O mesmo se observa em relação ao número de citações em jornais e magazines nacionais e internacionais. $\mathrm{Na}$ Revista Universo Contábil foi encontrado somente um artigo em que constava o termo "Controladoria" no título, no resumo e nas palavras-chave (Tabela 5).

Tabela 5 - Referências dos artigos publicados sobre Controladoria na Revista Universo Contábil

\begin{tabular}{|c|c|c|c|c|c|}
\hline Tipo de Bibliografia & & Total por tipo & $\%$ & Total geral & $\%$ \\
\hline \multirow{2}{*}{ Livros } & Nacional & 14 & 100 & 14 & 100 \\
\cline { 2 - 6 } & Internacional & 0 & 0 & 0 & 0 \\
\hline Total & & $\mathbf{1 4}$ & $\mathbf{1 0 0}$ & $\mathbf{1 4}$ & $\mathbf{1 0 0}$ \\
\hline
\end{tabular}

Fonte: dados da pesquisa

No único artigo publicado pela Revista Universo Contábil em que figura o termo Controladoria, foram citados como referências bibliográficas 14 livros, todos de publicação nacional. 
Análise Bibliométrica dos Artigos sobre Controladoria Publicados em Periódicos dos Programas de Pós-Graduação em Ciências Contábeis Recomendados pela Capes

Adriano José da Silva, Jorge Ribeiro de Toledo Filho, Juliana Pinto

A Tabela 6 descreve as referências publicadas e citadas na Revista Universo Contábil até o ano 2000.

Tabela 6 - Referências publicadas e citadas na revista Universo Contábil até o ano de 2000

\begin{tabular}{|c|c|c|c|c|c|}
\hline Tipo de Bibliografia & & Até o ano 2000 & $\%$ & Total Geral & $\%$ \\
\hline \multirow{2}{*}{ Livros } & Nacional & 4 & 100 & 4 & 100 \\
\cline { 2 - 6 } & Internacional & 0 & 0 & 0 & 0 \\
\hline Total por período & & $\mathbf{4}$ & $\mathbf{1 0 0}$ & $\mathbf{0}$ & $\mathbf{1 0 0}$ \\
\hline
\end{tabular}

Fonte: dados da pesquisa

Foram citadas quatro obras publicadas antes do ano de 2000, todas representadas por livros nacionais, que correspondem ao percentual de $28,57 \%$ do total de citações anterior ao ano de 2000.

$\mathrm{Na}$ Tabela número 7, tem-se a categorização das obras citadas na Revista Universo Contábil publicadas posterior ao ano de 2000.

Tabela 7 - Referências Publicadas e Citadas na Revista Universo Contábil posterior ao ano de 2000

\begin{tabular}{|c|c|c|c|c|c|}
\hline Tipo de Bibliografia & & Depois de 2000 & $\%$ & Total Geral & $\%$ \\
\hline \multirow{2}{*}{ Livros } & Nacional & 10 & 100 & 10 & 100 \\
\cline { 2 - 6 } & Internacional & 0 & 0 & 0 & 0 \\
\hline Total por período & & $\mathbf{1 0}$ & $\mathbf{1 0 0}$ & $\mathbf{0}$ & $\mathbf{1 0 0}$ \\
\hline
\end{tabular}

Fonte: dados da pesquisa

Do total das obras citadas no artigo em que consta o termo "controladoria", 10 são referentes a livros publicados no Brasil e com ano de publicação superior ao ano de 2000 , correspondendo a $71,43 \%$ do total das citações encontradas. Portanto, não houve busca de outras fontes bibliográficas para a elaboração do artigo.

$\mathrm{Na}$ Brazilian Business Review (BBR), encontrou-se somente um artigo contendo o termo "Controladoria". As referências bibliográficas consultadas foram mais diversificadas, se comparadas com a revista anterior, conforme se observa na tabela 8. 
Análise Bibliométrica dos Artigos sobre Controladoria Publicados em Periódicos dos Programas de Pós-Graduação em Ciências Contábeis Recomendados pela Capes

Adriano José da Silva, Jorge Ribeiro de Toledo Filho, Juliana Pinto

Tabela 8 - Referências dos Artigos publicados sobre Controladoria na Brazilian Business Review

\begin{tabular}{|c|c|c|c|c|c|}
\hline Tipo de Bibliografia & & Total por tipo & $\%$ & Total geral & $\%$ \\
\hline \multirow{2}{*}{ Livros } & Nacional & 2 & 9,52 & 4 & 19,04 \\
\cline { 2 - 6 } & Internacional & 2 & 9,52 & 0 & 0 \\
\hline \multirow{2}{*}{ Periódicos } & Nacional & 1 & 4,76 & 13 & 61,9 \\
\cline { 2 - 6 } & Internacional & 12 & 57,14 & 0 & 0 \\
\hline \multirow{2}{*}{ Anais Eventos Científicos } & Nacional & 0 & 0 & 0 & 0 \\
\cline { 2 - 6 } & Internacional & 1 & 4,76 & 1 & 4,76 \\
\hline \multirow{2}{*}{ Jornais e Magazines } & Nacional & 0 & 0 & 0 & 0 \\
\cline { 2 - 6 } & Internacional & 3 & 14,3 & 3 & 14,3 \\
\hline \multicolumn{2}{|c|}{ Total } & $\mathbf{2 1}$ & $\mathbf{1 0 0}$ & $\mathbf{2 1}$ & $\mathbf{1 0 0}$ \\
\hline
\end{tabular}

Fonte: dados da pesquisa

Examinando as referências bibliográficas encontradas no artigo publicado na BBR, nota-se uma diversificação na bibliografia pesquisada. Foram citados quatro livros que correspondem a $19,04 \%$ do total das citações, sendo 2 de publicação nacional e 2 de publicação americana ou européia, correspondendo individualmente a $9,52 \%$ do total de citações. Não se encontrou no respectivo artigo referência a teses e dissertações nacionais ou internacionais, anais e eventos científicos nacionais, sites da web nacionais e internacionais, jornais e magazines nacionais e outros tipos nacionais e internacionais.

Foram citados 13 periódicos, que correspondem a $61,9 \%$ do total de citações. Sendo que dos periódicos citados somente um é publicado no Brasil e corresponde a $4,76 \%$, e 12 periódicos internacionais que representam $57,14 \%$ de todas as citações. Foi citada uma referência de anais e eventos científicos, sendo essa citação em evento internacional, que corresponde a $4,76 \%$ das citações. Ainda há a citação de 3 referências de jornais e magazines internacionais, correspondendo a $14,3 \%$ do total de citações.

$\mathrm{Na}$ Tabela 9, aparece a distribuição das publicações citadas nas referências bibliográficas do Periódico Brazilian Business Review até o ano 2000. 
Análise Bibliométrica dos Artigos sobre Controladoria Publicados em Periódicos dos Programas de Pós-Graduação em Ciências Contábeis Recomendados pela Capes

Adriano José da Silva, Jorge Ribeiro de Toledo Filho, Juliana Pinto

Tabela 9 - Referências publicadas e citadas no periódico Brazilian Business Review até o ano de 2000

\begin{tabular}{|c|c|c|c|c|c|}
\hline Tipo de Bibliografia & & Até o ano 2000 & $\%$ & Total Geral & $\%$ \\
\hline \multirow{2}{*}{ Livros } & Nacional & 1 & 7,69 & 2 & 15,38 \\
\cline { 2 - 6 } & Internacional & 1 & 7,69 & 0 & 0 \\
\hline \multirow{2}{*}{ Periódicos } & Nacional & 1 & 7,69 & 8 & 61,54 \\
\cline { 2 - 6 } & Internacional & 7 & 53,85 & 0 & 0 \\
\hline \multirow{2}{*}{ Jornais e Magazines } & Nacional & 0 & 0 & 0 & 0 \\
\cline { 2 - 6 } & Internacional & 3 & 23,08 & 3 & 23,08 \\
\hline Total por período & & $\mathbf{1 3}$ & $\mathbf{1 0 0}$ & $\mathbf{1 3}$ & $\mathbf{1 0 0}$ \\
\hline
\end{tabular}

Fonte: dados da pesquisa

Do total de 21 citações, 13 se referem a obras publicadas antes do ano de 2000, com um percentual de $61,90 \%$ das obras citadas. Não constam nesse artigo referências de teses e dissertações nacionais e internacionais, anais e eventos científicos e sites da web nacionais e internacionais, bem como jornais e magazines nacional e outros tipos de referências nacionais e internacionais.

Foram citados 2 livros publicados antes do ano de 2000, o que corresponde a um percentual de 15,38\%, sendo um livro publicado no Brasil e outro no exterior. Os periódicos citados (8) são majoritariamente estrangeiros.

$\mathrm{Na}$ Tabela 10 são apresentadas as publicações citadas posteriores ao ano de 2000.

Tabela 10 - Referências publicadas e citadas no Periódico Brazilian Business Review posterior ao ano de 2000

\begin{tabular}{|c|c|c|c|c|c|}
\hline Tipo de Bibliografia & & Depois de 2000 & \% & Total Geral & \% \\
\hline \multirow{2}{*}{ Livros } & Nacional & 1 & 12,5 & 2 & 25 \\
\cline { 2 - 6 } & Internacional & 1 & 12,5 & 0 & 0 \\
\hline \multirow{2}{*}{ Periódicos } & Nacional & 5 & 62,5 & 5 & 62,5 \\
\cline { 2 - 6 } & Internacional & 0 & 0 & 0 & 0 \\
\hline \multirow{2}{*}{ Anais Eventos Científicos } & Nacional & 0 & 0 & 1 & 0 \\
\cline { 2 - 6 } & Internacional & 1 & 12,5 & $\mathbf{8}$ & 12,5 \\
\hline Total por período & & $\mathbf{8}$ & $\mathbf{1 0 0}$ & & $\mathbf{1 0 0}$ \\
\hline
\end{tabular}

Fonte: dados da pesquisa 
Do total das publicações referenciados no artigo publicado, somente 8, ou seja, $38,10 \%$ foram publicadas após o ano de 2000 . Não foram referenciadas no artigo: teses e dissertações, sites da web, jornais e magazines e outros tipos, tanto nacionais quanto internacionais, bem como anais e eventos científicos nacionais e periódicos internacionais.

Dentre as bibliografias citadas destacam-se 5 periódicos nacionais, perfazendo um total de $62,5 \%$. Dos livros citados, um é nacional e outro estrangeiro, com cerca de $25 \%$ do total de publicações ou $12,5 \%$ individualmente. Foi citado um artigo de um evento internacional.

$\mathrm{Na}$ Revista Contemporânea de Contabilidade há a menção do termo "Controladoria" em apenas um artigo (Tabela 11).

Tabela 11 - Referências dos artigos publicados sobre Controladoria na Revista Contemporânea de Contabilidade

\begin{tabular}{|c|c|c|c|}
\hline \multirow{3}{*}{ Tipo de Bibliografia } & & Total por tipo & $\%$ \\
\hline \multirow{3}{*}{ Livros } & Nacional & 5 & 55,56 \\
\cline { 2 - 4 } & Internacional & 0 & 0 \\
\hline \multirow{3}{*}{ Peses e Dissertações } & Nacional & 1 & 11,11 \\
\cline { 2 - 4 } & Internacional & 0 & 0 \\
\hline \multirow{3}{*}{ Anais Eventos Científicos } & Nacional & 1 & 11,11 \\
\cline { 2 - 4 } & Internacional & 0 & 0 \\
\cline { 2 - 4 } & Nacional & 1 & 11,11 \\
\hline \multirow{2}{*}{ Sites Web } & Internacional & 0 & 0 \\
\cline { 2 - 4 } & Nacional & 1 & 11,11 \\
\hline \multirow{2}{*}{ Total } & Internacional & 0 & 0 \\
\hline
\end{tabular}

Fonte: dados da pesquisa 
Os livros nacionais citados na bibliografia representam $55,56 \%$ do total das citações encontradas, contabilizando-se 5 livros citados. Teses e dissertações nacionais, periódicos nacionais, anais e eventos científicos nacionais e sítios da web nacionais foram citados, respectivamente, uma vez cada, representando individualmente $11,11 \%$ do total pesquisado.

$\mathrm{Na}$ Tabela 12 figuram as referências publicadas e citadas na Revista Contemporânea de Contabilidade, anteriores ao ano de 2000.

Tabela 12 - Referências publicadas e citadas na Revista Contemporânea de Contabilidade até o ano de 2000

\begin{tabular}{|c|c|c|c|c|c|}
\hline \multirow{2}{*}{ Tipo de Bibliografia } & & Até o ano 2000 & $\%$ & Total Geral & $\%$ \\
\hline \multirow{2}{*}{ Livros } & Nacional & 5 & 83,33 & 5 & 83,33 \\
\cline { 2 - 6 } & Internacional & 0 & 0 & 0 & 0 \\
\hline \multirow{2}{*}{ Teses e Dissertações } & Nacional & 1 & 16,67 & 1 & 16,67 \\
\cline { 2 - 6 } & Internacional & 0 & 0 & 0 & 0 \\
\hline \multirow{2}{*}{ Total por período } & & $\mathbf{6}$ & $\mathbf{1 0 0}$ & & $\mathbf{1 0 0}$ \\
\hline
\end{tabular}

Fonte: dados da pesquisa

Ao examinar as referências citadas na Revista Contemporânea de Contabilidade, nota-se que 6 obras são publicadas antes do ano de 2000, num total de $60.97 \%$. São citados 5 livros nacionais publicados antes do ano 2000, com um percentual de $83,33 \%$ das obras citadas. Há somente uma tese e/ou dissertação nacional citada, num percentual de $16,67 \%$ do total de citações. 
Análise Bibliométrica dos Artigos sobre Controladoria Publicados em Periódicos dos Programas de Pós-Graduação em Ciências Contábeis Recomendados pela Capes

Adriano José da Silva, Jorge Ribeiro de Toledo Filho, Juliana Pinto

Tabela 13 - Referências publicadas e citadas na Revista Contemporânea de Contabilidade, posteriores ao ano de 2000

\begin{tabular}{|c|c|c|c|c|c|}
\hline \multirow{2}{*}{ Tipo de Bibliografia } & & Depois de 2000 & $\%$ & Total Geral & $\%$ \\
\hline \multirow{2}{*}{ Periódicos } & Nacional & 1 & 33,33 & 1 & 33,33 \\
\cline { 2 - 6 } & Internacional & 0 & 0 & 0 & 0 \\
\hline \multirow{2}{*}{ Anais Eventos Científicos } & Nacional & 1 & 33,33 & 1 & 33,33 \\
\cline { 2 - 6 } & Internacional & 0 & 0 & 0 & 0 \\
\hline \multirow{2}{*}{ Sites Web } & Nacional & 1 & 33,33 & 1 & 33,33 \\
\cline { 2 - 6 } & Internacional & 0 & 0 & 0 & 0 \\
\hline \multirow{2}{*}{ Total por período } & & $\mathbf{3}$ & $\mathbf{1 0 0}$ & $\mathbf{0}$ & $\mathbf{1 0 0}$ \\
\hline
\end{tabular}

Fonte: dados da pesquisa

Há somente 3 citações de publicações posteriores ao ano de 2000, num percentual de 33,33\%, sendo: um periódico nacional, um artigo em anais de evento científico em nível nacional e um site da web nacional, correspondendo a 33,33\% cada bibliografia referenciada.

\section{CONSIDERAÇÕES FINAIS}

Esta pesquisa selecionou artigos publicados onde constavam o termo "Controladoria", no título, no resumo ou nas palavras-chave, de periódicos editados nos Programas de Mestrado em Ciências Contábeis recomendados pela CAPES, visando analisar a bibliografia referenciada.

A pesquisa revela que a Revista Contabilidade \& Finanças da FEA-USP apresenta mais artigos publicados onde consta o termo pesquisado. Há uma maior bibliografia referenciada, tanto no que tange a publicações nacionais quanto internacionais. A revista é publicada desde 1989 e nela foram selecionados e analisados seis artigos. 
Na Revista Universo Contábil, editada na Universidade Regional de BlumenauFURB, há referência no artigo publicado de somente um livro nacional contemplando o termo "Controladoria".

Na Revista Brazilian Business Review, há também um único artigo publicado, sendo referenciados na bibliografia mais periódicos, sendo esses predominantemente internacionais.

Na Revista Contemporânea de Contabilidade, editada na Universidade Federal de Santa Catarina - UFSC percebe-se a utilização de livros nacionais predominantemente na elaboração do artigo publicado.

Como resultado final da análise bibliométrica realizada, constata-se que 55,4\% das referências utilizadas nos artigos pesquisados são internacionais, o que revela a existência de um amplo espaço para pesquisas sobre Controladoria no Brasil.

\section{REFERÊNCIAS}

BEUREN, Ilse Maria. (2002). O papel da controladoria no processo de gestão. In: SCHMIDT, Paulo (Org.) Controladoria: agregando valor para a empresa. Porto Alegre: Bookman.

BORINELLI, Márcio Luiz. (2006). Estrutura conceitual básica de controladoria: sistematização à luz da teoria e da práxis. São Paulo. (Tese de Doutorado). Programa de Pós-graduação em Ciências Contábeis, Departamento de Contabilidade e Atuária, FEA-USP.

BUFREM, L; Prates Yara. O saber científico registrado e as práticas de mensuração da informação. Instituto Brasileiro de Informação em Ciência e Tecnologia - IBICT. disponível em: www.ibict.br. Acesso em 12/dez/2007.

CAPES. Disponível em: http://www.capes.gov.br. Acesso em: 24/Fev/2007.

CATELLI, Armando (Coord.). (2001). Controladoria: uma abordagem da gestão econômica - GECON. (2 ed.). São Paulo: Atlas.

CERVO, A. L; BERVIAN, P. A. (2002). Metodologia científica. (5 ed.). São Paulo: Prentice Hall. 
PELEIAS, Ivam Ricardo. (2002). Controladoria: gestão eficaz utilizando padrões. São Paulo: Saraiva.

PRITCHARD, A. (1969). Statistical bibliography or bibliometrics. Journal of Documentation, London, v. 25, n. 4, p. 348-349, Dec.

RAUPP, Fabiano Maury. BEUREN, Ilse Maria. (2004). Caracterização da Pesquisa em Contabilidade. In. BEUREN, Ilse Maria (Org). Como elaborar trabalhos monográficos em contabilidade: teoria e prática. (2 ed.). São Paulo: Atlas.

RICHARDSON, Roberto Jarry. (2004). Metodologia da pesquisa aplicável às ciências sociais. In: Beuren, Ilse Maria (org). Como elaborar trabalhos monográficos em contabilidade: teoria e prática. (2 ed.). São Paulo: Atlas.

RíOS, D. R. (2000). The Bibliometrics: Penetration level in the university teaching of library science and its application in the librarian field in the countries of Mercosur. (66th). IFLA Council and General Conference. Jerusalem, v. 7, n. 127, p. 4-5, August.

SAES. S.G. Estudo bibliométrico das publicações em economia da saúde, no Brasil 1989-1998. (Dissertação de Mestrado). Programa de Pós-Graduação em Administração, Serviços de Saúde, Faculdade de Saúde Pública, Universidade de São Paulo.

Data de Submissão: 02/02/2009

Data de Aceite: 23/04/2009 